\title{
Changes in the Plasma Membrane of Regenerating Protoplasts of Candida albicans as Revealed by Freeze-fracture Electron Microscopy
}

\author{
By FERNANDO MIRAGALL, HORTENSIA RICO AND \\ RAFAEL SENTANDREU* \\ Department de Microbiologia, Facultat de Farmacia, Universitat de Valencia, \\ Avgda. Blasco Ibañez 13, 46010 Valencia, Spain
}

(Received 7 March 1985; revised 14 May 1986)

\begin{abstract}
Modifications occurring in the plasma membrane and their relationship to newly synthesized microfibrils were examined in regenerating protoplasts of Candida albicans by freeze-fracture electron microscopy. Freshly prepared protoplasts showed no residual wall material, and long invaginations covered the surface of the plasma membrane. Analysis of the external face (Eface) of the plasma membrane showed a significant decrease in the number of intramembranous particles (IMP) in comparison with the original cells. After 40 min incubation in regeneration medium, newly synthesized microfibrils which seemed to originate from protrusions in the plasma membrane were observed. The plasma membrane showed important modifications with respect to IMP. After $3 \mathrm{~h} 45 \mathrm{~min}$, the cells were covered by an abnormal wall which showed isolated fibrils partially embedded in the matrix material. The plasma membrane of these partially regenerated protoplasts was similar to that of original cells. After $8 \mathrm{~h}$, regeneration of the protoplasts seemed to be complete as no differences from the original cells were detected in the plasma membrane or the wall. Calcofluor white altered the deposition of wall polymers during regeneration, but did not modify the plasma membrane of the protoplasts.
\end{abstract}

\section{INTRODUCTION}

Synthesis of structural polysaccharides and their subsequent assembly in microfibrils are fundamental events in the formation of higher plant walls, and it is believed that the plasma membrane plays an essential role in both processes (Northcote, 1974). The structure of the plasma membrane has been studied by freeze-fracture in various plant species (Willison \& Cocking, 1972; Willison, 1976; Willison \& Brown, 1978; Herth \& Hausser, 1984); however, little is known about its role in wall synthesis in fungi. The process of wall regeneration by protoplasts may be an adequate model to investigate the involvement of the plasma membrane in the formation of microfibrillar polymers and other wall components, and to study the way they interact once free in the periplasmic space. There are two advantages of using protoplasts in these types of studies: (i) masking of interactions between nascent wall polymers by the walls in growing cells does not occur or is reduced in protoplasts (Elorza et al., 1983b), and (ii) the synthesis of wall polymers is dramatically increased in protoplasts (Elorza et al., 1983a). Candida albicans protoplasts can regenerate a whole new wall in only a few hours (Elorza et al., 1983a), but protoplasts of Saccaromyces cerevisiae and other fungal species regenerate more slowly and do not revert into normal cells in liquid media (Nečas \& Svoboda, 1976; Svoboda \& Piedra, 1983). The microfibrillar nets produced by $S$. cerevisiae and other fungi have been reported to be composed of glucan and/or chitin (Nečas \& Svoboda, 1985), but almost nothing is known about the involvement of the plasma membrane on these microfibrils.

Abbreviation: IMP, intramembranous particles. 
Freeze-fracture electron microscopy allows visualization of the fibril nets and other wall components laid down during regeneration, and also permits the detection of modifications on the plasma membrane and inside the bilayer because cleavage occurs mainly at the hydrophobic interface (Branton, 1966). In the present work we investigated wall regeneration by protoplasts of $C$. albicans in liquid media using the above technique. Special attention was paid to the interactions between nascent wall fibrils and plasma membrane elements, and to the events that occurred on the plasma membrane during wall regeneration. The effect of calcofluor white on this process was also investigated.

\section{METHODS}

Organism. Candida albicans ATCC 26555 was used. It was maintained by subculturing every 2-3 weeks on slopes of Sabouraud-dextrose agar, and grown according to Elorza et al. (1983b).

Protoplast preparation. Cells $\left(100 \mathrm{mg}\right.$ dry $\left.\mathrm{wt}^{-1}\right)$ were suspended in the treatment medium $(50 \mathrm{~mm}$ dithiothreitol, $5 \mathrm{~mm}$-EDTA and $0.5 \mathrm{mg}$ pronase $\mathrm{ml}^{-1}$ ), incubated at $30^{\circ} \mathrm{C}$ for $30 \mathrm{~min}$, then washed with distilled water and suspended in Zymolyase $5000\left(2 \mathrm{mg} \mathrm{ml}^{-1}\right.$, Kirin Breweries, Co. $)$ in $6 \mathrm{ml} 0.6 \mathrm{M}-\mathrm{KCl}$.

Regeneration of protoplasts. Protoplasts were regenerated at $28^{\circ} \mathrm{C}$ in the medium of Lee et al. (1975) supplemented with $0.6 \mathrm{M}-\mathrm{KCl}$ as osmotic stabilizer and, in some experiments, with calcofluor white $\left(50 \mu \mathrm{g} \mathrm{ml}^{-1}\right)$.

Freeze-fracture method. Intact cells and regenerating protoplasts at times $0 \mathrm{~min}, 40 \mathrm{~min}, 90 \mathrm{~min}, 3 \mathrm{~h} 45 \mathrm{~min}$ and $8 \mathrm{~h}$ were fixed with $2.5 \%(\mathrm{v} / \mathrm{v})$ glutaraldehyde in $0.6 \mathrm{M}-\mathrm{KCl}$ for several hours and cryoprotected by passage through a graded series of glycerol solutions $(10,20$ and $30 \%, v / v)$. The samples were then frozen in liquid Freon 22 and stored in liquid nitrogen. Fracturing was done at $-110^{\circ} \mathrm{C}$ in a Balzers $360 \mathrm{M}$ unit at a pressure of $267 \mu \mathrm{Pa}$. The fracture surface was shadowed with carbon-platinum at an angle of $45^{\circ}$ and carbon was then evaporated at an angle of $90^{\circ}$. The replicas were cleaned in $\mathrm{NaOCl}$ (active chlorine $8 \%$ ) and $40 \%(\mathrm{w} / \mathrm{v})$ chromic acid and then washed in distilled water. Replicas were examined in a Jeol $100 \mathrm{~S}$ electron microscope.

The density and size of the intramembranous particles were determined on micrographs at a final magnification of $\times 60000$, with the aid of a calibrated magnifying glass (Miragall, 1983). Statistical analysis of quantitative results was done by Student's $t$ test $(P \leqslant 0.025)$.

\section{RESULTS}

Freeze-fracture replicas of blastospores and mycelial cells of Candida albicans displayed a thick wall made up of two distinct layers: an internal one with a rough fibrillar appearance and an external one with an amorphous texture (Fig. 1). The P-face of the plasma membrane had numerous intramembranous particles (IMP) $10.4 \pm 1.4 \mathrm{~nm}$ in diameter (mean \pm SD) and with similar shape. Invaginations about $140-280 \mathrm{~nm}$ long and $33-42 \mathrm{~nm}$ wide were also observed randomly distributed on the plasma membrane. They appeared as grooves in the P-face (Fig. $1 a$, c) and as complementary ridges in the E-face (Fig. 1 b). The invaginations contained few IMP on either membrane face; however, they were of ten bordered by a row of particles $12.0 \pm 1.2 \mathrm{~nm}$ in diameter (Fig. 1b).

Freshly prepared protoplasts showed no remains of wall material. They exhibited significant structural modifications in the plasma membrane: thus, whereas the size $(10.5 \pm 1.6 \mathrm{~nm})$ and morphology of the IMP were similar to those of normal cells, the numerous invaginations initially detected had disappeared but others about $1-2 \mu \mathrm{m}$ long or even longer and 33-42 nm wide (Fig. $2 a, b$ ) crossing the plasma membrane were observed. They appeared again as grooves in the P-face (Fig. $2 a$ ) and as ridges in the E-face (Fig. 2b). The invaginations were not uniform channels but showed a rosary-like structure due to successive swellings along their long axis (Fig. $2 a, b$ ). They seemed also to be bordered by IMP $12 \cdot 6 \pm 2 \cdot 3 \mathrm{~nm}$ in diameter (Fig. $2 c$ ).

After 40-90 min regeneration, fibrils of wall material originating from the plasma membrane were observed (Fig. 3). At the same time, the aspect of the plasma membrane had changed dramatically: on P-faces small conical protrusions appeared randomly distributed (Fig. $3 a$ ). On the E-face pits complementary to the protrusions were found (Fig. $4 a$ ). When fibrils were longitudinally fractured, and their origin at the most proximal portion was observed, they seemed to extrude from the protrusions (Fig. $3 c$ ). Furthermore, the long invaginations typically observed in non-regenerating protoplasts (Fig. 2) became flattened into strips 0.33-2.6 $\mu \mathrm{m}$ long and $42-58 \mathrm{~nm}$ wide, showing hardly any IMP (Fig. $4 a, b$ ). On the P-face, the area outside the original invaginations showed numerous IMP randomly distributed and with a heterogeneous 

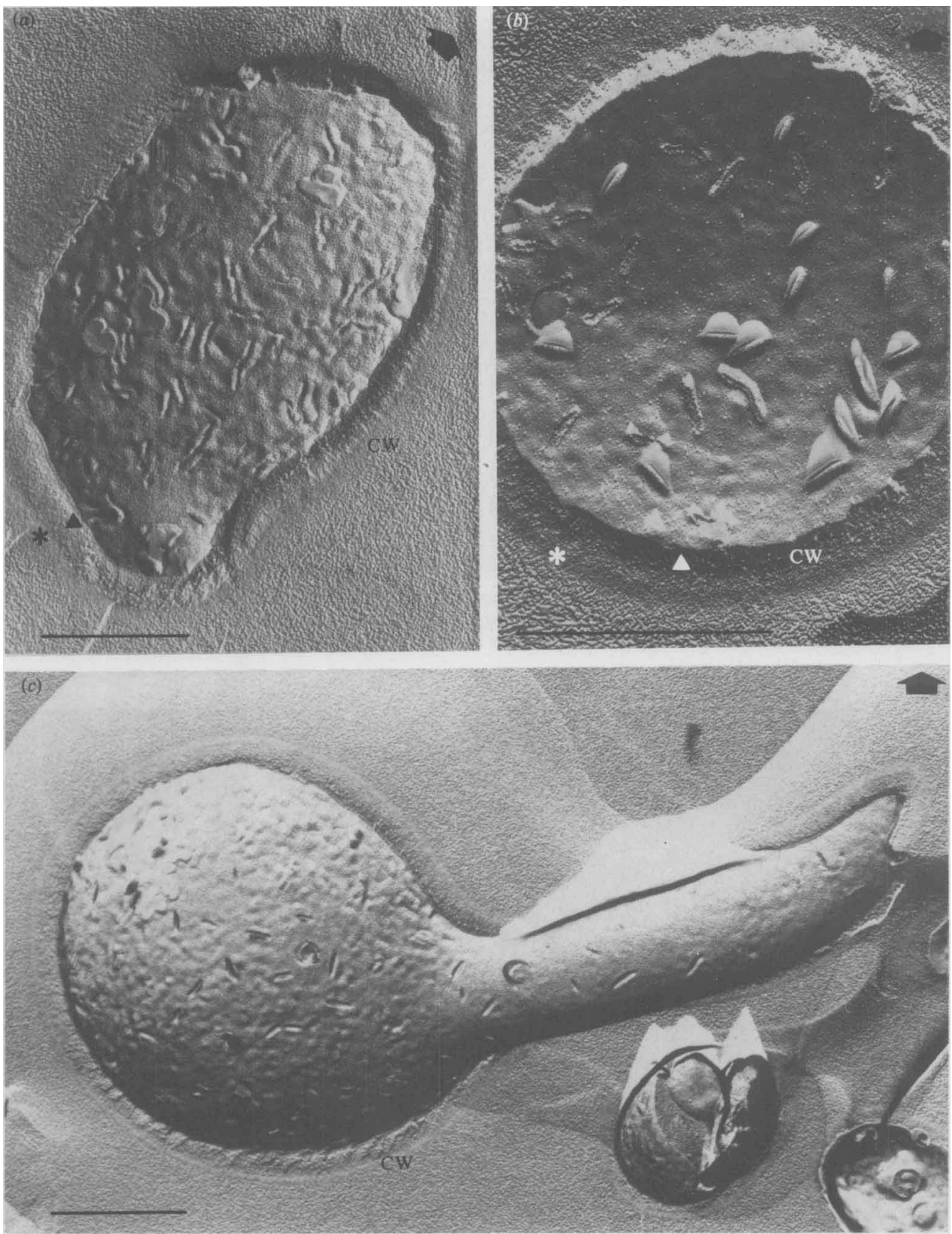

Fig. 1. $(a, b)$ Yeast cells of $C$. albicans showing a well-developed wall (CW), in which two layers can be distinguished: an external smooth one (*), and an internal fibrillar one (A). (a) P-face, (b) E-face of the plasma membrane; note that the P-face bears far more particles than the E-face. (c) Mycelial cell of $C$. albicans. Note the presence of the wall $(\mathrm{CW})$ and invaginations. These are more numerous in the blastospore than in the germ tube. Bars, $1 \mu \mathrm{m}$. A thick arrow indicates the direction of shadowing in all figures. 

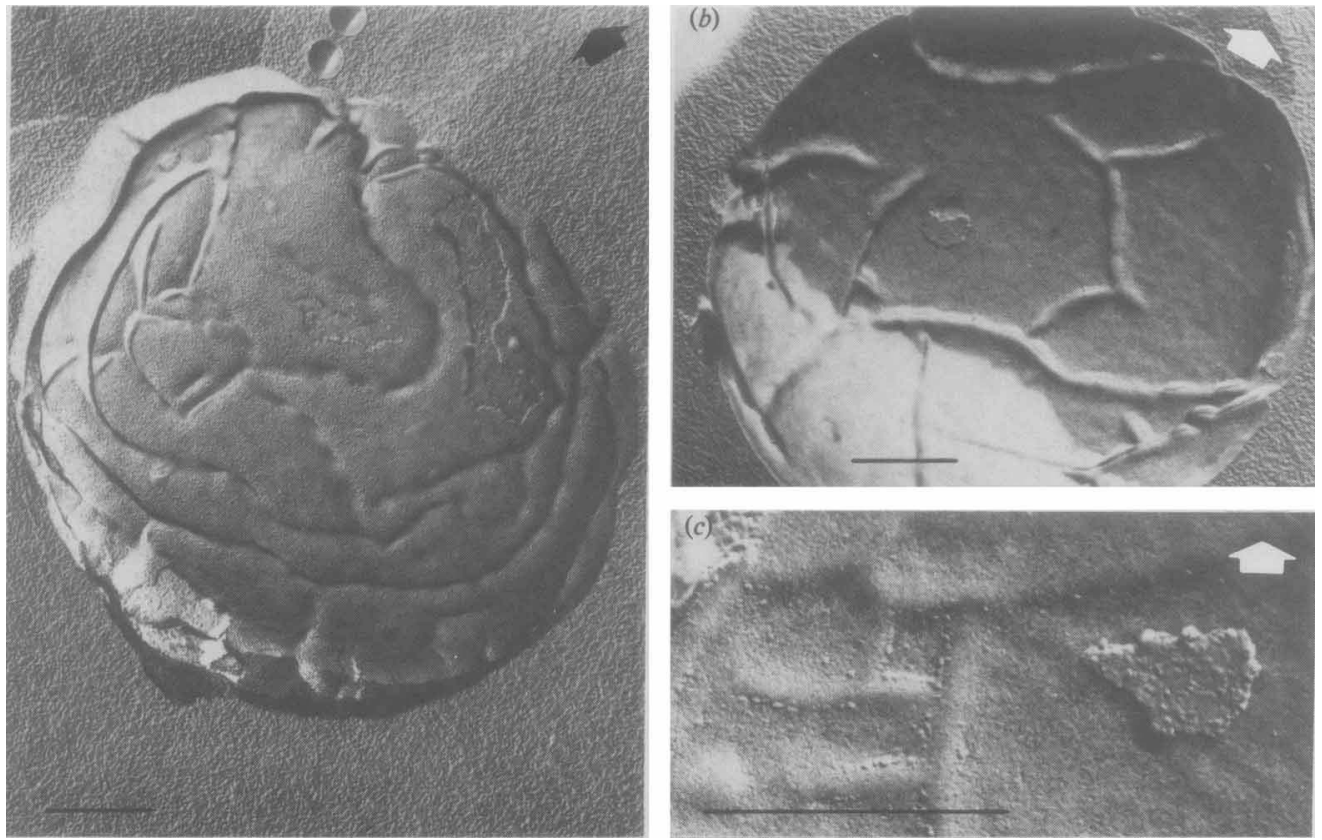

Fig. 2. Freshly prepared protoplasts of $C$. albicans. Note the long invaginations, probably formed by coalescence of those found in cells. Invaginations appeared as grooves in the P-face $(a)$ and as ridges in the E-face $(b, c)$. (c) Detail of rows of particles bordering the invaginations. Bars, $0.5 \mu \mathrm{m}$.
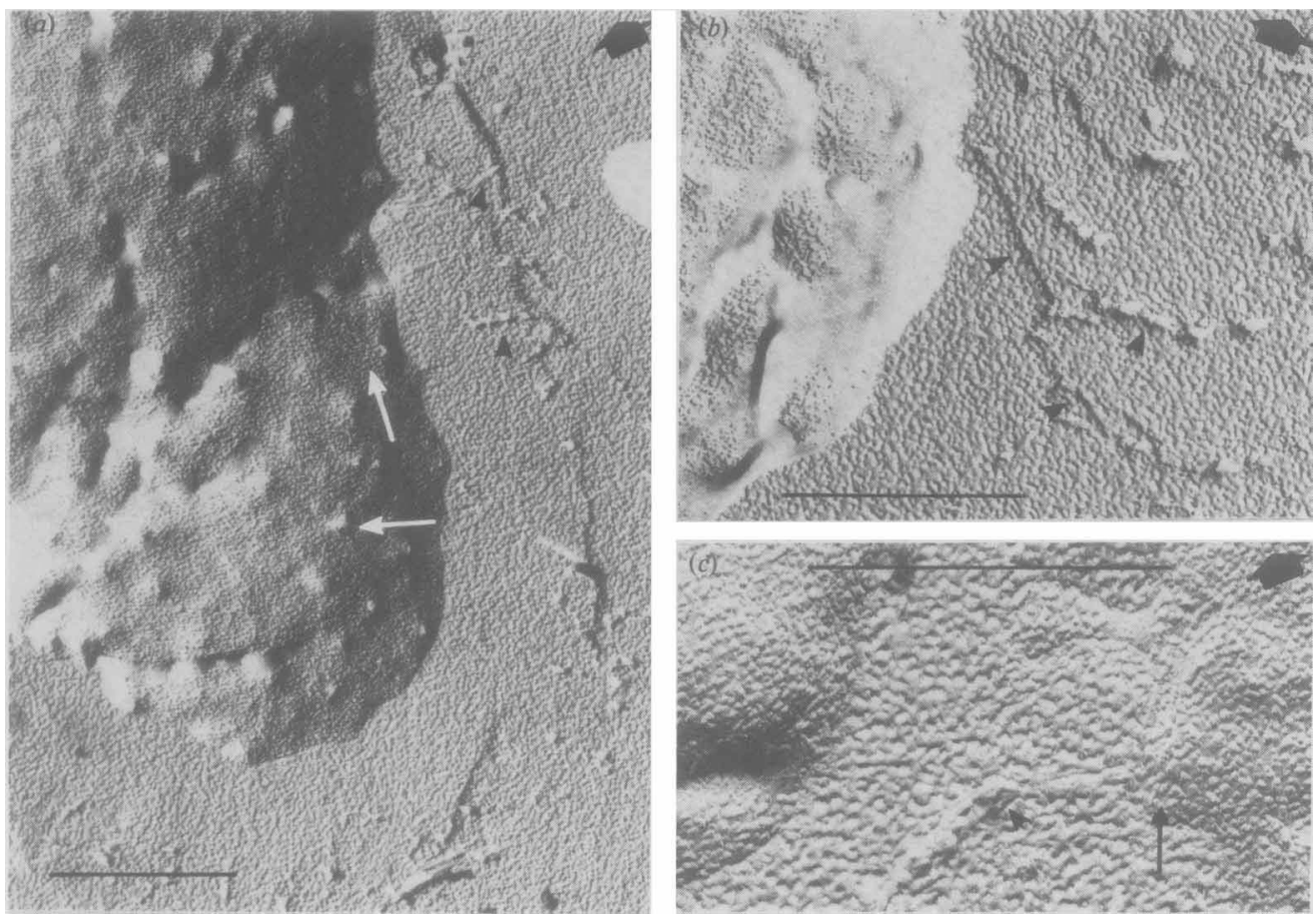

Fig. 3. Protoplasts after $40 \mathrm{~min}$ regeneration. (a) Numerous conical protrusions (arrows), and fibrils (arrowheads) surrounding the protoplast; $(b)$ detail of the fibrils (arrowheads) at this stage of regeneration; (c) detail of a microfibril (arrowhead) originating from a conical protrusion (arrow). Bars, $0.5 \mu \mathrm{m}$. 

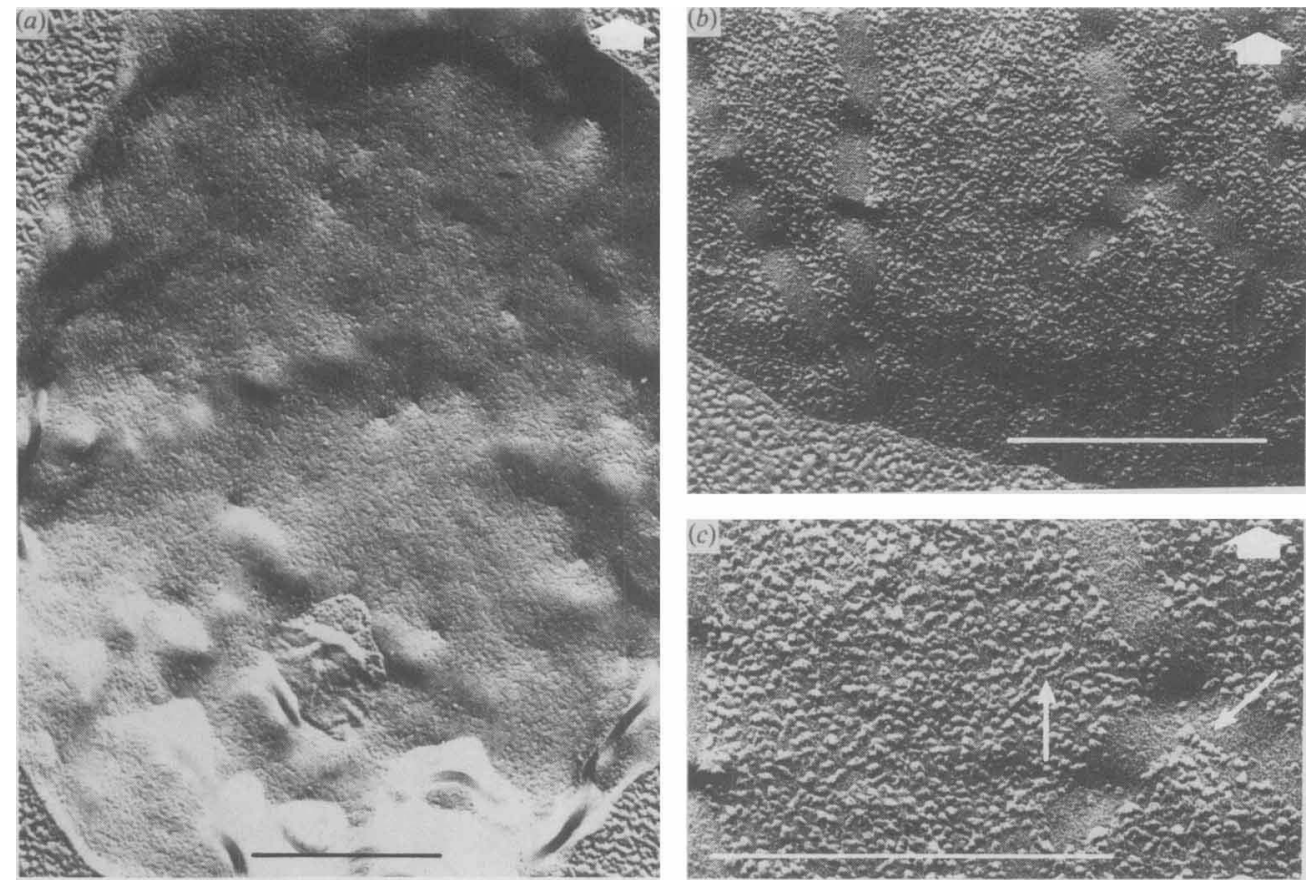

Fig. 4. (a) Protoplasts after $90 \mathrm{~min}$ regeneration. Conical protrusions appear in the E-face as invaginations; pits complementary to IMP are also observed in this fracture face. $(b)$ Protoplasts after 40 min regeneration showing strips almost completely devoid of IMP. Note that IMP are very heterogeneous at this phase of regeneration. (c) Detail from $(b)$ showing the heterogeneous morphology of IMP. The arrows point to quadruple particles. Bars, $0.5 \mu \mathrm{m}$.
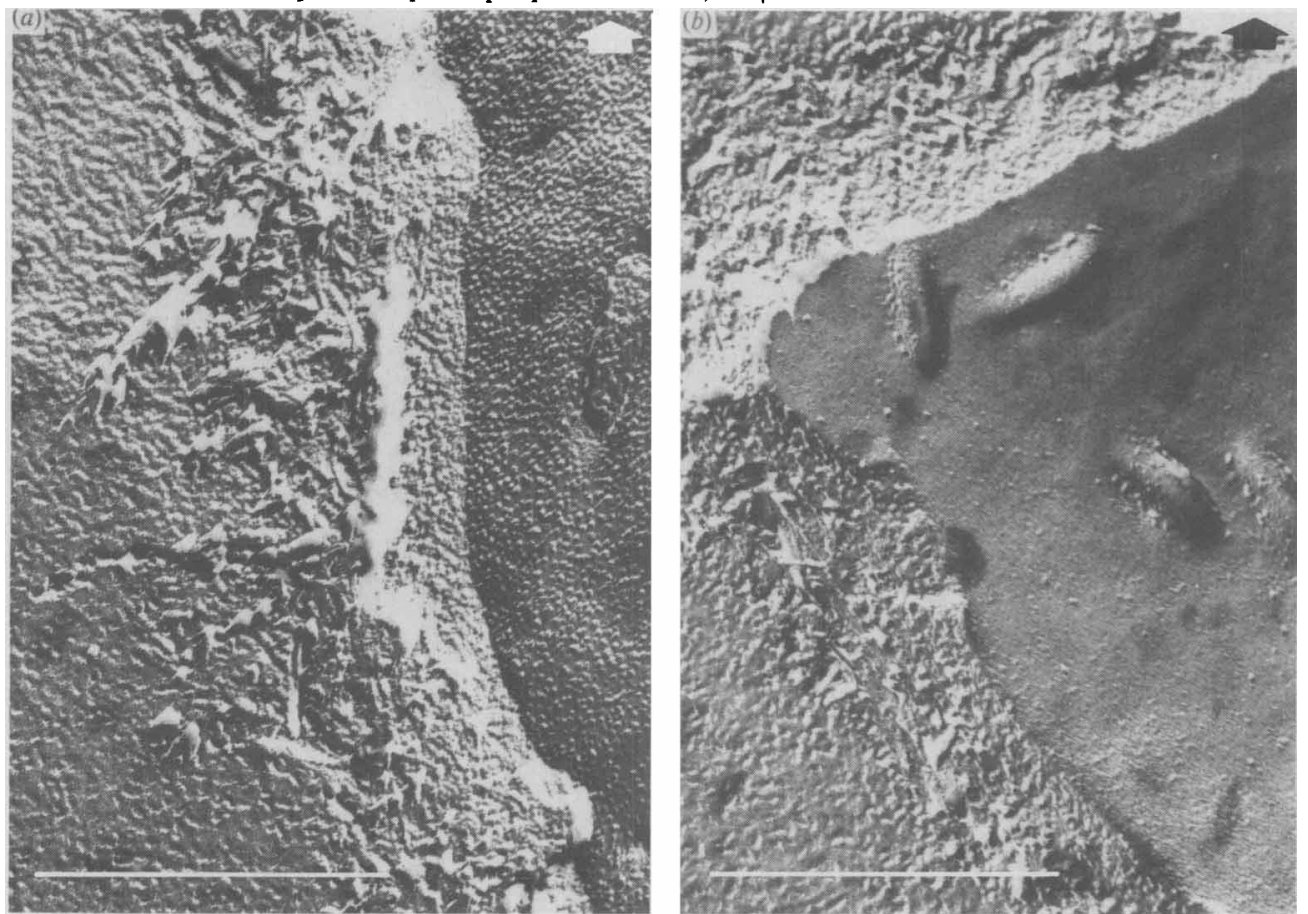

Fig. 5. Later stages in protoplast regeneration. After $3 \mathrm{~h} 45 \mathrm{~min}$ incubation, the wall is not yet completely constructed and fibres have not been totally cemented. Both P-face $(a)$ and E-face $(b)$ show a morphology similar to that found in the original intact cells. Notice also rows of particles bordering the invaginations. Bars, $0.5 \mu \mathrm{m}$. 

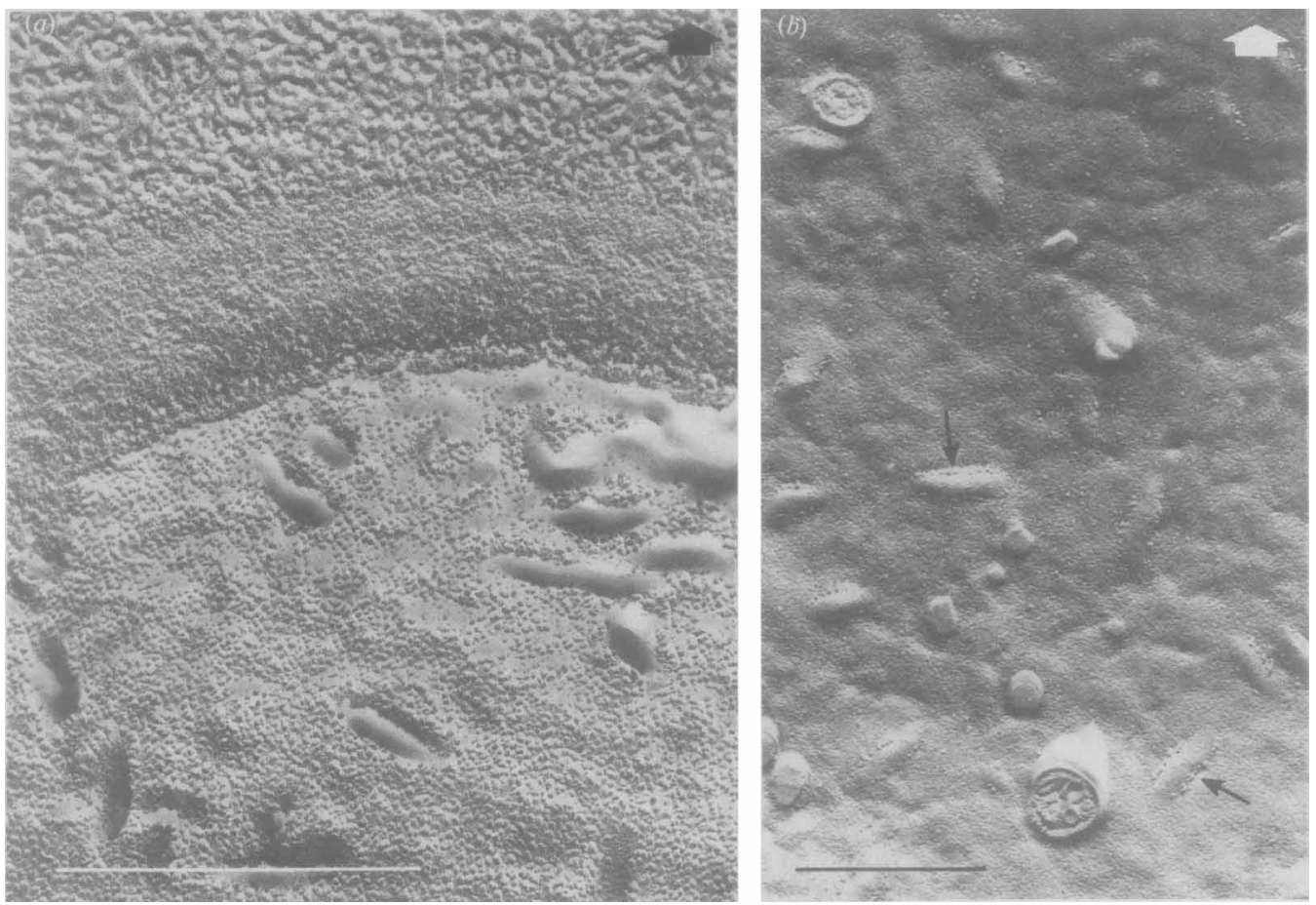

Fig. 6. Cells after $8 \mathrm{~h}$ regeneration, in which both wall and plasma membrane are identical to those of original intact cells. In the E-face $(b)$ short invaginations (arrows) bordered by rows of particles are observed. Bars, $0.5 \mu \mathrm{m}$.
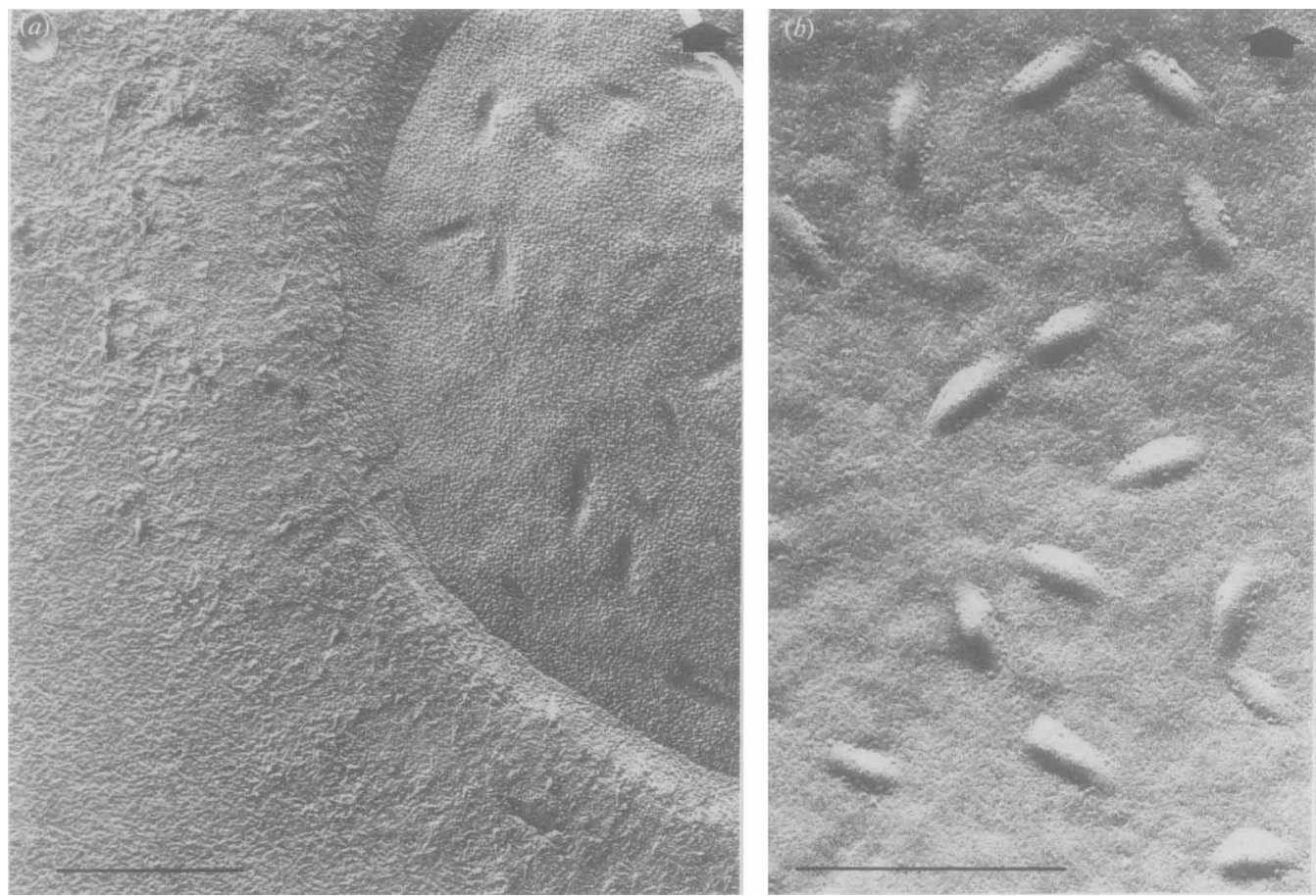

Fig. 7. Cells regenerated in the presence of calcofluor white, after $8 \mathrm{~h}$. (a) A P-face. Note that the wall maintains a fibrillar aspect, as if incompletely compacted. The plasma membrane has a similar aspect to that of control cells (Fig. 6a). (b) An E-face also depicting numerous invaginations bordered by particles. Bars, $0.5 \mu \mathrm{m}$. 
Table 1. Densities of IMP (per $\mu \mathrm{m}^{2}$, mean $\pm \mathrm{SD}$ ) of plasma membranes from C. albicans blastospores, mycelia and protoplasts at different times of regeneration

$\begin{array}{lcrc} & & & \begin{array}{c}\text { P-face } \\ + \\ \text { E-face }\end{array} \\ \text { Blastospores } & \text { P-face } & \text { E-face } & 3602 \cdot 9 \\ \text { Mycelia } & 3227 \cdot 9 \pm 406 \cdot 0 & 375 \cdot 0 \pm 79 \cdot 8 & 3647 \cdot 7 \\ \text { Protoplasts } t=0 \mathrm{~min} & 3328 \cdot 4 \pm 329 \cdot 5 & 319 \cdot 3 \pm 72 \cdot 4 & 3268 \cdot 6 \\ \text { Protoplasts } t=40 \mathrm{~min} & 3177 \cdot 6 \pm 221 \cdot 6 & 91 \cdot 0 \pm 37 \cdot 4 & 2354 \cdot 9 \\ \text { Protoplasts } t=90 \mathrm{~min} & 2323 \cdot 3 \pm 236 \cdot 8 & 31 \cdot 6 \pm 14 \cdot 8 & 2283 \cdot 1 \\ \text { Protoplasts } t=3 \mathrm{~h} 45 \mathrm{~min} & 2244 \cdot 0 \pm 305 \cdot 5 & 39 \cdot 1 \pm 22 \cdot 8 & 3611 \cdot 3 \\ \text { Protoplasts } t=8 \mathrm{~h} & 3241 \cdot 3 \pm 255 \cdot 1 & 370 \cdot 2 \pm 132 \cdot 4 & 3408 \cdot 0\end{array}$

morphology, and at least four different populations of IMP were distinguished: a main population (about $73 \%$ of the total) consisting of single particles, and another three populations formed respectively of aggregations of two (double particles; about $20.5 \%$ ), three (triple particles; about $5 \%$ ) and four (quadruple particles; about $2.5 \%$ ) IMP (Fig. $4 c$ ). E-faces showed numerous pits complementary to IMPs found on the P-face.

After $3 \mathrm{~h} 45 \mathrm{~min}$ regeneration, the cells already showed a discrete wall with two regions: an internal one that seemed to be very compact, and an external one whose fibrils had not yet been cemented by amorphous material (Fig. 5). At this stage of regeneration the morphology of the plasma membrane was similar to that found in normal growing cells. IMP measuring $10.2 \pm 1.4$ $\mathrm{nm}$, and short invaginations (150-420 nm long and 43-58 $\mathrm{nm}$ wide), were found (Fig. 5).

After $8 \mathrm{~h}$ regeneration, both wall and plasma membrane were indistinguishable from those of original cells. In the plasma membranes IMP measuring $10.3 \pm 1.5 \mathrm{~nm}$ and short invaginations (150-333 $\mathrm{nm}$ long and 42-51 $\mathrm{nm}$ wide) were observed (Fig. 6). The latter were bordered by a row of IMP about $12 \mathrm{~nm}$ in diameter. The density distribution of IMP $\left(\mu \mathrm{m}^{-2}\right)$ on P- and E-faces of plasma membranes from blastospores, mycelia, newly obtained protoplasts and protoplasts at the different regeneration times investigated are summarized in Table 1. Invaginations were not considered in these measurements.

Protoplasts regenerating in the presence of calcofluor white showed some differences in the morphology of the cell wall in comparison with those regenerating in its absence: at late stages of regeneration the cell walls mainly showed a loose texture (Fig. $7 a$ ). In contrast, the morphology of the plasma membrane did not differ from that of normally regenerating protoplasts (Fig. 7).

\section{DISCUSSION}

Since protoplasts of $C$. albicans synthesize new walls and revert to normal vegetative cells when incubated in liquid medium, wall formation can be studied without the impediments of pre-existing structures. The regeneration process is initiated by the deposition of fibrils mainly composed of chitin as deduced from their chemical composition (Elorza et al., 1983a) and their reaction with calcofluor white (Elorza et al., 1983b) and with wheatgerm agglutinin (unpublished results). This deposition of fibrils is the result of the metabolic activity of the protoplasts, and is reflected cytologically at the level of the plasma membrane. In normal growing cells the plasma membrane possesses short invaginations whose functional significance is not clearly understood (Moor \& Muhlethaler, 1963; Streiblova, 1968; Hereward \& Northcote, 1972; Nečas \& Svoboda, 1976; Sekiya \& Nozawa, 1983; Takeo, 1984). The original short invaginations of the plasma membrane seem to fuse longitudinally during protoplast formation suggesting that they are permanent structures of the plasma membrane. After $40 \mathrm{~min}$ incubation, the resulting long rosary-like invaginations become flattened, suggesting that the protoplasts are initially limited by a defined amount of plasma membrane. Presumably the formation of the protrusions and/or the increase in their mass and, as a consequence, their volume uses significant amounts of membrane and flattens the invaginations. The protrusions 
behave as permanent structures that invaginate again following the addition of newly synthesized membrane material. We suggest that the in vaginations could represent reservoirs of membrane material. Rosettes and other arrangements of membrane particles have been implicated in the formation of cellulose and chitin microfibrils (Giddings et al., 1980; Mueller \& Brown, 1980; Herth, 1983; Herth \& Hauser, 1984). We did not observe rosettes or arrays of particles in the membrane of regenerating $C$. albicans protoplasts, but the outgrowing fibrils did originate from small conical protrusions. These structures seem to be involved in wall formation and they could represent the initial location of the chitin synthase complexes (Cabib et al., 1983) that subsequently spread over the whole plasma membrane (Elorza et al., 1983b). After $3 \mathrm{~h}$ $45 \mathrm{~min}$ the fibrils were seen partially immersed in a matrix material which is probably composed of proteins (Elorza et al., 1985). After $8 \mathrm{~h}$ regeneration, the original protoplasts looked like normal growing cells. This was not the case with protoplasts incubated in the presence of low concentrations of calcofluor white, a reagent which does not alter polymerization of chitin but which interferes with formation of the crystalline lattice. Due to this effect protoplasts appear surrounded by a fluorescent halo (Elorza et al., 1983b). Calcofluor treatment resulted in a wall covered with very long elementary fibrils that had not been assembled into normal fibres.

IMP are discontinuities in the fracture plane through the lipid matrix of the membranes, and in eukaryotic cells, they are believed to be proteinaceous (Verkleij \& Ververgaert, 1978; Fujimoto \& Ogawa, 1980; Murphy \& Swift, 1983). E-faces of the plasma membrane from newly obtained protoplasts had a significantly lower concentration of IMP than the original cells (Table 1), indicating that in C.albicans digestion of the cell wall also affects the proteins attached to the E-face of the plasma membrane. Between 40 and 90 min regeneration, the density of IMP on both P-and E-faces decreased significantly with respect to that of original cells. Moreover, particles consisting of aggregations of two, three and even four single IMP were observed on Pfaces, accounting for almost $28 \%$ of the total amount of IMP. However, considering single particles as one particle, double as two particles, triple as three and quadruple as four particles, the value of IMP $\mu \mathrm{m}^{-2}$ obtained was about 3200 , which did not differ from the IMP density of original cell plasma membranes. This suggests a diminution of the amount of membrane proteins visualized as IMP, and/or a reorganization of these components taking place during these phases of regeneration, in which the synthesis of cell wall materials is greatly enhanced. On the other hand, at these times of regeneration E-faces showed complementarity (pits complementary to IMP). This feature has been described in the outer membrane of Escherichia coli (Van Alphen et al., 1978; Verkleij \& Ververgaert, 1978), in which IMP are lipopolysaccharide-protein complexes. These observations suggest that at least part of the IMP of protoplast plasma membranes at these phases of regeneration might contain polysaccharides and materials that would contribute to the formation of the new cell wall. Using cytochemical and freeze-fracture methods, glycoproteins were found to be associated with IMP in S. cerevisiae (Maurer \& Muhlethaler, 1981). Our results, however, differ from those of Nečas \& Svoboda (1976), who reported no differences in structure and density of IMP in the plasma membrane during reversion of $S$. cerevisiae protoplasts. Finally, after 3 h 45 min and 8 h regeneration both the morphology and density of IMP of plasma membranes appeared similar to those of original cells, implying that at these stages of regeneration, the plasma membrane has already reached the initial equilibrium.

The authors thank G. Voss-Wermbter for excellent technical assistance. This work was financially supported by the Spanish Comisión Asesora de Investigación Científica y Técnica (grant no. 3432-83), Fondo de Investigaciones Sanitarias, and a stipend from the Fundación Juan March to F. M.

\section{REFERENCES}

Branton, D. (1966). Fracture faces of frozen membranes. Proceedings of the National Academy of Sciences of the United States of America 55, 10481056.

Cabib, E., Bowers, B. \& Roberts, R. L. (1983).
Vectorial synthesis of a polysaccharide by isolated plasma membrane. Proceedings of the National Academy of Sciences of the United States of America 30, 3318-3321.

Elorza, M. V., Rico, H., Gozalbo, D. \& 
SENTANDREU, R. (1983a). Cell wall composition and protoplast regeneration in Candida albicans. Antonie van Leeuwenhoek 49, 457-469.

Elorza, M. V., Rico, H. \& SentandReu, R. (1983b). Calcofluor white alters the assembly of chitin fibrils in Saccharomyces cerevisiae and Candida albicans cells. Journal of General Microbiology 129, 15771582.

Elorza, M. V., Murgui, A. \& Sentandreu, R. (1985). Dimorphism in Candida albicans: contribution of mannoproteins to the architecture of yeast and mycelial cell walls. Journal of General Microbiology 131, 2209-2216.

Fujimoto, T. \& OGawa, K. (1980). Intramembranous particles on freeze-fractured membrane replica and sulfhydryl groups. Histochemistry 65, 217-222.

Giddings, T. H., JR, Brower, D. L. \& Staehelin, L. A. (1980). Visualization of particle complexes in the plasma membrane of Micrasterias denticulata associated with the formation of cellulose fibrils in primary and secondary cell walls. Journal of Cell Biology 84, 327-339.

Hereward, F. V. \& NoRThCOTE, D. H. (1972). Localization of freeze-fracture planes of yeast membranes. Journal of Cell Science 10, 555-561.

HERTH, W. (1983). Arrays of plasma membrane 'rosettes' involved in cellulose microfibril formation of Spirogyra. Planta 159, 347-356.

Herth, W. \& Hausser, I. (1984). Chitin and cellulose fibrillogenesis in vivo and their experimental alteration. In Structure and Biosynthesis of Plant Cell Walls, pp. 89-119. Edited by W. M. Dugger \& S. BartnickiGarcia. Baltimore: Waverly Press.

Lee, K. L., Buckley, M. R. \& Campbell, C. (1975). An aminoacid liquid synthetic medium for development of mycelial and yeast forms of Candida albicans. Sabouraudia 13, 148-153.

Maurer, A. \& Muhlethaler, K. (1981). Specific labelling of glycoproteins in yeast plasma membrane with Concanavalin A. European Journal of Cell Biology 25, 58-65.

Miragall, F. (1983). Evidence for orthogonal arrays of particles in the plasma membranes of olfactory and vomeronasal sensory neurons of vertebrates. Journal of Neurocytology 12, 567-576.

MoOR, H. \& MUHLETHALER, K. (1963). Fine structure in frozen-etched yeast cells. Journal of Cell Biology 17, 609-629.
Mueller, S. C. \& Brown, R. M., JR. (1980) Evidence for an intramembrane component associated with a cellulose microfibril-synthesizing complex in higher plants. Journal of Cell Biology 84, 315-326.

MURPhY, C. R. \& SwifT, J. G. (1983). Pronase reduces intramembranous particle density in uterine epithelial cells in vivo. Acta Anatomica 116, 174-179.

NEČAS, O. \& SvobOdA, A. (1976). Regeneration of yeast protoplasts. A freeze-etching study. Zeitschrift für allgemeine Mikrobiologie 16, 615-625.

NeČAs, O. \& Svoboda, A. (1985). Cell wall regeneration and protoplast reversion. In Fungal Protoplasts, vol. 6, pp. 115-133. Edited by J. Peberdy \& L. Ferenczy. New York \& Basel: Marcel Dekker.

NoRTHCOTE, D. M. (1974). Membrane systems of plant cells. Philosophical Transactions of the Royal Society B268, 119-128.

SekiYA, T. \& Nozawa, Y. (1983). Reorganization of membrane ergosterol during cell fission event of Candida albicans: a freeze-fracture study of distribution of filipin-ergosterol complexes. Journal of Ultrastructural Research 83, 48-57.

Streiblova, E. (1968). Surface structure of yeast protoplasts. Journal of Bacteriology 95, 700-707.

Svoboda, A. \& PIEDRA, D. (1983). Reversion of yeast protoplasts in media containing polyethylene glycol. Journal of General Microbiology 129, 3371-3377.

TAKEO, K. (1984). Lack of invaginations of the plasma membrane during budding and cell division of Saccharomyces cerevisiae and Schizosaccharomyces pombe. FEMS Microbiology Letters 22, 97-100.

VAN AlPhen, L. VerkleiJ, A., LeunisSen-BiJRelt, J. \& LUGTENBERG, B. (1978). Architecture of the outer membrane of Escherichia coli. III. Protein-lipopolysaccharide complexes in intramembranous particles. Journal of Bacteriology 134, 1089-1098.

Verkleis, A. J. \& Ververgaert, P. H. J. Th. (1978). Freeze-fracture morphology of biological membranes. Biochimica et biophysica acta 515, 303-327.

WILlison, J. H. M. (1976). An examination of the relationship between freeze-fractured plasmalemma and cell wall microfibrils. Protoplasma 88, 187-200.

Willison J. H. M. \& Brown, R. M. (1978). Cell wall structure and deposition in Glaucocystis. Journal of Cell Biology 77, 103-119.

Willison, J. H. M. \& Cocking, E. C. (1972). The production of microfibrils at the surface of isolated tomato-fruit protoplasts. Protoplasma 75, 397-403. 